\title{
Bilateral lower limb hypoesthesia after radical prostatectomy in the hyperlordotic position under general anesthesia
}

\author{
[Hypoesthésie bilatérale des membres inférieurs après prostatectomie radicale \\ sous anesthésie générale en position d'byperlordose]
}

Hélène Beloeil MD, ${ }^{*}$ Pierre Albaladejo MD, ${ }^{*}$ Sophie Hoen MD, ${ }^{*}$ Pascal Eschwege MD, $†$ Dan Benhamou MD*

Purpose: To report a case of postoperative bilateral lower limb hypoesthesia occurring after surgery under general anesthesia in the hyperlordotic position for radical prostatectomy. The possible pathophysiologic mechanisms are discussed.

Clinical features: This 52-yr-old patient was slightly overweight and was on fenofibrate for hypercholesterolemia. He had no history of cardiovascular disease. Arterial blood pressure was overall well maintained except for a very transient hypotension at surgical incision. Blood loss was moderate and did not require transfusion. Soon after recovery, the patient complained of paresthesia in both legs and neurological examination revealed bilateral lower limb hypoesthesia, compatible with an incomplete medullar syndrome at the level of TI2-LI. On postoperative day one, a plain magnetic resonance imaging scan demonstrated a hyperintense signal in the spinal cord from T8 to T9 on T2-weighted images consistent with ischemia of the spinal cord whereas the heterogeneous aspect of the spinal cord was due to an unusually high fat content of the epidural space. Neurological signs improved progressively and one week later the patient had recovered normal sensory functions of both lower limbs.

Conclusion: Although arterial ischemia is the most common cause of postoperative spinal cord injury, other mechanisms may be invoked. We raise the possibility that a combination of intraoperative risk factors (hypotension, excessive postural changes) with anatomic predispositions (increased epidural venous pressure or fat content, previous bone disease) can produce arterial and/or venous ischemia of the spinal cord.
Objectif : Rapporter un cas d'atteinte neurologique postopératoire bilatérale des membres inférieurs après prostatectomie radicale sous anesthésie générale et en position d'hyperlordose. Les mécanismes physiopathologiques possibles sont discutés.

Eléments cliniques : Un homme de 52 ans, légèrement obèse et traité par un fibrate pour une hypercholestérolémie n'avait aucune histoire cardiovasculaire clinique et ses explorations paracliniques étaient négatives. La pression artérielle a peu baissé au cours de l'intervention à l'exception d'une hypotension transitoire et modérée lors de l'incision. Les pertes sanguines modérées n'ont pas justifié de transfusion. Dès son réveil, le patient s'est plaint de paresthésies des deux membres inférieurs et l'examen clinique montrait une hypoesthésie bilatérale des membres inférieurs avec un niveau supérieur TI2-LI. L'imagerie par résonnance magnétique médullaire réalisée le lendemain montrait un hypersignal en mode T2 de T8 à T9. L'aspect hétérogène de la moelle était considéré comme secondaire à une accumulation graisseuse dans l'espace péridural. L'évolution fut complètement favorable en une semaine.

Conclusion : Bien que l'ischémie artérielle soit la cause la plus fréquente des atteintes neurologiques bilatérales des membres inférieurs postopératoires, d'autres mécanismes peuvent être impliqués ou associés. Ce cas soulève la possibilité que des mécanismes peropératoires (hypotension, modifications posturales excessives) puissent s'associer à des facteurs pré-existants (augmentation de la pression veineuse épidurale ou anomalies osseuses) pour créer une ischémie artérielle et/ou veineuse de la moelle.

From the Departments of Anesthesiology, ${ }^{*}$ and Urology, † Hôpital de Bicêtre, Assistance Publique-Hôpitaux de Paris, Le Kremlin Bicêtre, France.

Address correspondence to: Pr Dan Benhamou, Department of Anesthesiology, Hôpital de Bicêtre, 94275 Le Kremlin Bicêtre Cedex,

France. Phone: 33-1-45213447; Fax: 33-1-45212875; E-mail: dan.benhamou@bct.ap-hop-paris.fr

Accepted for publication December 26, 2002.

Revision accepted May 2, 2003. 


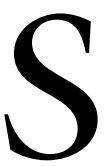

PINAL cord injuries are well-recognized postoperative complications. Anticoagulation, epidural anesthesia or analgesia, spine surgery and positioning have been associated with neuraxial postoperative complications. ${ }^{1}$ These factors co-exist frequently in reported cases ${ }^{2-4}$ and the respective role of each mechanism is difficult to clarify.

We describe a case of postoperative bilateral lower limb hypoesthesia occurring after radical prostatectomy in the hyperlordotic position under general anesthesia, in the absence of neuraxial anesthesia. The magnetic resonance imaging (MRI) showed a small area of spinal cord ischemia. Although several case reports describing similar scenarios have already been published, ${ }^{2-4}$ this remains an unusual situation. Anesthesiologists are well aware of neurological complications related to arterial hypotension or arterial clamping and of deleterious consequences of regional anesthesia. They are, however, less informed on other factors causing ischemia, the co-existence of which is often required for catastrophes to occur.

\section{Case report}

A 54-yr-old man, American Society of Anesthesiologists physical status II, was scheduled for radical prostatectomy. The patient had cardiovascular risk factors: hypercholesterolemia treated by fenofibrate and active smoking. His body mass index was 27.5. An arterial ultrasound performed one year before surgery did not reveal any atheromatous disease of the aorta, lower limb and cervical arteries. The preoperative blood pressure was $130 / 60 \mathrm{mmHg}$ and the electrocardiogram was normal. He had no clinical history of any spine disease. Prostatectomy was performed under general anesthesia in a supine but moderately hyperlordotic position. The scheduled epidural analgesia was not performed because prophylactic anticoagulants had been administered on the preoperative day. Anesthesia was induced with propofol and sufentanil, maintained with desflurane and nitrous oxide. Paralysis was achieved with atracurium. After induction, the patient was placed in a hyperlordotic position on the operating table, with a folded sheet used as a wedge under the sacrum. Blood pressure was measured by oscillometry at the arm. Throughout the procedure, blood pressure ranged between $100 / 50$ and $120 / 70 \mathrm{mmHg}$ except for a transient decrease in blood pressure $(80 / 40 \mathrm{mmHg})$ lasting less than ten minutes occurring at the time of surgical incision. Hypotension was easily corrected by ephedrine $6 \mathrm{mg}$. No arrhythmia occurred. Blood loss was estimated to be $1000 \mathrm{~mL}$. The patient was kept in a hyperlordotic position during four hours. Emergence from anesthesia was uneventful. After arrival in the recovery

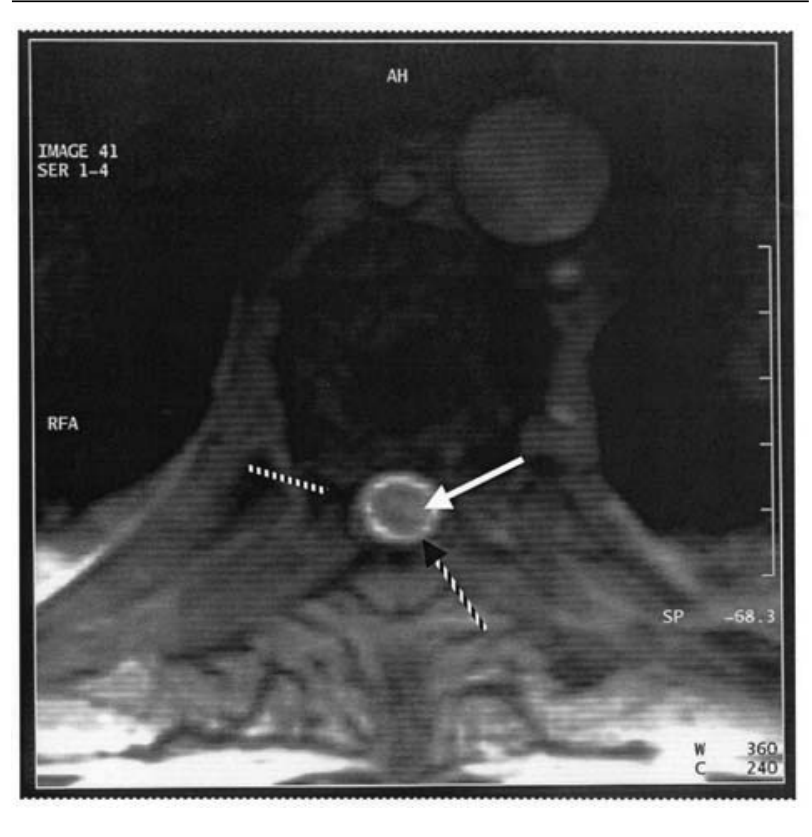

FIGURE Magnetic resonance imaging of the lumbar spine on day one. Hyperintense signal in the spinal cord from T8 to T9 (white line). Unusually important fat content of the epidural space (dashed lines).

room, the patient complained of paresthesias in both legs. Neurological examination revealed hypoesthesia (pinprick and cold perception) of both lower limbs with no motor deficit. The cutaneous plantar reflex was positive on both sides. Patellar jerk reflexes were decreased and ankle jerk reflexes were abolished bilaterally. There was no clinical sign of ischemia (peripheral pulses were all present). Symptoms were compatible with an incomplete medullar syndrome at the level of T12-L1, predominating on the posterior spinal cord. On postoperative day one, a plain MRI scan of the lumbar spine was performed (Figure). A hyperintense signal in the spinal cord from T8 to T9 was visible on T2weighted images. The heterogeneous aspect of the spinal cord was due to an unusually important fat content of the epidural space. MRI signs were consistent with ischemia of the spinal cord. Neurological signs improved progressively and one week later the patient had recovered normal sensory functions of both lower limbs and was discharged from the hospital.

\section{Discussion}

We have described a case of postoperative bilateral lower limb hypoesthesia, which occurred after a fourhour surgical procedure in the hyperlordotic position under general anesthesia. Neurological evaluation and 
MRI were compatible with ischemia of the posterior part of the lumbar spinal cord. How could spinal cord ischemia occur? How could the hyperlordotic position cause ischemia? Can practical attitudes be modified on the grounds of this information?

Of those cases of postoperative neurologic abnormalities or paraplegia already reported in the literature, several were related to a unique cause such as epidural hematoma, abscess, or neurotoxicity of the local anesthetic used. Thus, in most cases, regional anesthesia had been performed. The limited number of published cases involving only general anesthesia probably results from a publication bias. Regional anesthesia is indeed "easy to blame" and the idea that paraplegia is unequivocally due to the associated spinal anesthesia is misleading because several mechanisms and anatomical particularities may also be responsible.

Ischemic injury can indeed lead to postoperative spinal cord complications. The most usual pattern is arterial ischemia. A spinal artery syndrome may be secondary to a direct lesion of the anterior spinal artery or to a decrease in arterial supply, be it the consequence of marked and/or prolonged hypotension or aortic clamping above the Adamkiewicz artery. ${ }^{5}$ In our patient, because decreased blood pressure was shortlived and because the patient had no vascular disease, arterial ischemia was unlikely. Ischemia of venous origin, by contrast, could easily explain what we observed. The transient nature and the rapid complete recovery might well support this hypothesis. Venous ischemia may indeed result from volume changes of any of the components of the perimedullar space and increased venous pressure can lead to spinal venous infarction. Hyperlordosis causes a rotation of the liver and obstruction of the inferior vena cava in its intrahepatic course. Pressure increases within the accessory venous pathway (i.e., the azygos system) and is transmitted via the intercosto-vertebral veins and epidural venous plexuses to the intraspinal veins. Spinal cord injury can also be due to a decreased epidural space secondary to a spinal stenosis or to an increased epidural fat content. Using MRI to study the different tissue components of the extradural space, Hirabayashi et al. ${ }^{6}$ have shown that 1 ) the extradural fat varied in shape and size depending on the vertebral level; 2) the effective capacity of the medullar space is dependent on the importance of the extradural fat. Moreover, spinal cord compression has been described in various diseases ${ }^{7,8}$ resulting from an increase in extradural fat. However, each of these anatomic particularities (spinal stenosis, increased epidural fat content and increased venous pressure) may be observed in many patients while the occurrence of spinal cord ischemia is very unusual. In addition, con- tributing anatomic factors are found in several other situations in which spinal cord ischemia is not observed. For example, during pregnancy, Igarashi et al. ${ }^{9}$ showed that the epidural venous pressure is consistently increased whereas neurological complications are, fortunately, exceptional. This suggests that important changes (i.e., profound prolonged hypotension or postural change, high fat content...) or a combination of factors are required for spinal ischemia to occur. Spinal cord compression may result from pagetic spinal stenosis exaggerated by an increase in extradural fat. ${ }^{10}$ In our patient, spinal cord compression may have been induced by the combined action of increased epidural fat content and hyperlordosis-induced increased venous pressure. Such ischemic injuries on the venous side may also be worsened by a decrease in spinal perfusion pressure due to hypotension. ${ }^{11,12}$

Since postoperative paraparesis might be explained by positioning during general anesthesia, it would be useful to define risk factors. Unfortunately, the literature is desperately poor on this topic. The potentially deleterious role of spinal stenosis has been related to spinal anesthesia ${ }^{13}$ but the relationship between general anesthesia and spinal ischemia remains unclear in this context. However, because postoperative paraplegia is an exceptional complication, it remains difficult to define risk factors precisely. We suggest that hypotension and hyperlordosis be minimized in patients in whom preoperative contributing factors (bone disease, increased epidural venous pressure or fat content) are found.

\section{Conclusion}

A case of a postoperative bilateral lower limb hypoesthesia, which occurred after a surgical procedure in the hyperlordotic position under general anesthesia and most likely unrelated to arterial hypotension, is described. Imaging was compatible with an ischemic mechanism. This raises the possibility that the combination of intraoperative risk factors (mild hypotension, excessive postural changes) with anatomic predispositions (increased epidural venous pressure or fat content, previous bone disease) can increase the risk of postoperative spinal cord injury.

\section{References}

1 Cheney FW, Domino KB, Caplan RA, Posner KL. Nerve injury associated with anesthesia. A closed claims analysis. Anesthesiology 1999; 90: 1062-9.

2 Amoiridis G, Wobrle JC, Langkafel M, Maiwurm D, Przuntek $H$. Spinal cord infarction after surgery in a patient in the hyperlordotic position. Anesthesiology 1996; 84: 228-30. 
3 Konstantinidou AS, Balamoutsos NG. Paraplegia in a patient who by chance missed the insertion of an epidural catheter (Letter). Anesth Analg 1996; 82: 1110.

4 De Souza Neto EP, Andreo R, Kopp C, Long D, Marechal JM, Bouletreau P. Paraplegia after cystectomy and epidural anesthesia (Letter). Anesthesiology 2000; 92: 632-3.

5 Biglioli P, Spirito R, Roberto $M$, et al. The anterior spinal artery: the main arterial supply of the human spinal cord - a preliminary anatomic study. J Thorac Cardiovasc Surg 2000; 119: 376-9.

6 Hirabayashi $\Upsilon$, Saitoh K, Fukuda H, Igarashi T, Shimizu $R$, Seo N. Magnetic resonance imaging of the extradural space of the thoracic spine. Br J Anaesth 1997; 79: 563-6.

7 Guegan $\Upsilon$, Fardoun R, Launois B, Pecker J. Spinal cord compression by extradural fat after prolonged corticosteroid therapy. J Neurosurg 1982; 56: 267-9.

8 Lee M, Lekias J, Gubbay SS, Hurst PE. Spinal cord compression by extradural fat after renal transplantation. Med J Aust 1975; 1: 201-3.

9 Igarashi T, Hirabayashi Y, Shimizu R, Saitoh K, Fukuda $H$, Suzuki $H$. The fiberscopic findings of the epidural space in pregnant women. Anesthesiology 2000; 92: 1631-6.

10 Hepgul K, Nicoll JA, Coakham HB. Spinal cord compression due to pagetic spinal stenosis with involvement of extradural soft tissues: a case report. Surg Neurol 1991; 35: 143-6.

11 Urquhart-Hay D, Teague CA. Spinal trombophlebitis after prostatectomy with hypotensive anaesthesia; case report. N Z Med J 1974; 79: 654-6.

12 Urquhart-Hay D. Paraplegia following epidural analgesia. Anaesthesia 1969; 24: 461-70.

13 Tetzlaff JE, Dilger JA, Wu C, Smith MP, Bell G. Influence of lumbar spine pathology on the incidence of paresthesia during spinal anesthesia. Reg Anesth Pain Med 1998; 23: 560-3. 